\title{
A suggested emergency medicine boot camp curriculum for medical students based on the mapping of Core Entrustable Professional Activities to Emergency Medicine Level I milestones
}

\author{
This article was published in the following Dove Press journal: \\ Advances in Medical Education and Practice \\ I March 2016 \\ Number of times this article has been viewed
}

\section{Sangeeta Lamba \\ Bryan Wilson \\ Brenda Natal \\ Roxanne Nagurka \\ Michael Anana \\ Harsh Sule}

Department of Emergency Medicine, Rutgers New Jersey Medical School, Newark, NJ, USA
Correspondence: Roxanne Nagurka Department of Emergency Medicine, Rutgers New Jersey Medical School, I50 Bergen Street, Newark, NJ 07I0 I, USA

Email nagurkrm@gsbs.rutgers.edu
Background: An increasing number of students rank Emergency Medicine (EM) as a top specialty choice, requiring medical schools to provide adequate exposure to EM. The Core Entrustable Professional Activities (EPAs) for Entering Residency by the Association of American Medical Colleges combined with the Milestone Project for EM residency training has attempted to standardize the undergraduate and graduate medical education goals. However, it remains unclear as to how the EPAs correlate to the milestones, and who owns the process of ensuring that an entering EM resident has competency at a certain minimum level. Recent trends establishing specialty-specific boot camps prepare students for residency and address the variability of skills of students coming from different medical schools.

Objective: Our project's goal was therefore to perform a needs assessment to inform the design of an EM boot camp curriculum. Toward this goal, we 1) mapped the core EPAs for graduating medical students to the EM residency Level 1 milestones in order to identify the possible gaps/ needs and 2) conducted a pilot procedure workshop that was designed to address some of the identified gaps/needs in procedural skills.

Methods: In order to inform the curriculum of an EM boot camp, we used a systematic approach to 1) identify gaps between the EPAs and EM milestones (Level 1) and 2) determine what essential and supplemental competencies/skills an incoming EM resident should ideally possess. We then piloted a 1-day, three-station advanced $\mathrm{ABC}$ s procedure workshop based on the identified needs. A pre-workshop test and survey assessed knowledge, preparedness, confidence, and perceived competence. A post-workshop survey evaluated the program, and a posttest combined with psychomotor skills test using three simulation cases assessed students' skills.

Results: Students $(n=9)$ reported increased confidence in the following procedures: intubation (1.5-2.1), thoracostomy (1.1-1.9), and central venous catheterization (1.3-2) (a three-point Likerttype scale, with $1=$ not yet confident/able to perform with supervision to $3=$ confident/able to perform without supervision). Psychomotor skills testing showed on average, $26 \%$ of students required verbal prompting with performance errors, $48 \%$ with minor performance errors, and $26 \%$ worked independently without performance errors. All participants reported: 1) increased knowledge and confidence in covered topics and 2) overall satisfaction with simulation experience.

Conclusion: Mapping the Core EPAs for Entering Residency to the EM milestones at Level 1 identifies educational gaps for graduating medical students seeking a career in EM. Educators designing EM boot camps for medical students should consider these identified gaps, procedures, and clinical conditions during the development of a core standardized curriculum.

Keywords: emergency medicine, clerkship, medical education, competency, EPA 10, milestones 


\section{Introduction}

Emergency Medicine (EM) has experienced unprecedented growth in graduate medical education with the expansion of residency programs nationwide. ${ }^{1}$ An increasing number of US medical students rank EM as a top specialty choice. ${ }^{1}$ Undergraduate programs are incorporating EM experiences in their curricula, but the addition of mandatory, structured EM clerkships still remains an area of slow growth., Unlike primary-care specialties such as Internal Medicine or Pediatrics where core standardized clerkship curricula ensure that each graduating US medical student has certain knowledge and skills related to that discipline, this is not so for EM. Medical schools may offer elective EM experiences, but these may have wide variability in goals, settings, and focus, as evidenced by differences between community versus tertiary-care center rotations, pediatrics versus adult EM experiences, and exposure to trauma and ultrasound. Therefore, currently, there may be considerable variability from one medical school graduate to another in the knowledge and skills related to EM.

Program directors across specialties are concerned over the variability in skill sets and lack of preparedness of incoming residents. ${ }^{4}$ In response to these concerns, efforts are being made to better define expectations during physician training with the development of the Core Entrustable Professional Activities (EPAs) for Entering Residency by the Association of American Medical Colleges (AAMC). ${ }^{5,6}$ The EPAs are a clear, concise list of what graduating medical students should be entrusted to do without direct supervision on DAY ONE of any residency. ${ }^{7,8}$ The entrustment in the tasks of professional practice is important to note and means that a student can perform the task unsupervised. ${ }^{7,8}$ EPAs therefore define activities of an entrusted learner and offer a clear definition of what is expected and what can be measured and observed, once a competency has been achieved, regardless of specialty. For example, gather a history and perform a medical examination is a discrete measurable EPA. There are 13 EPAs currently defined and each includes a list of expected behaviors and vignettes that describe the entrustable learner. While every EPA applies to a resident entering EM training, EPA 10 states Recognize a patient requiring urgent or emergent care and initiate evaluation and management, which typifies a core competency of EM.

As part of the New Accreditation System, the American Board of Emergency Medicine (ABEM) and the Accreditation Council for Graduate Medical Education (ACGME) established 23 milestones that EM residents are expected to achieve to varying levels throughout their training. ${ }^{9}$
Milestones are knowledge, skills, and attitudes for each of the competencies such as patient care (PC), professionalism (PROF), and interpersonal and communication skills (ICS), organized in a developmental framework from less to more advanced. They describe tasks for evaluating the performance of a resident from entry into residency through graduation. Level 1 is expected of an incoming resident, Level 4 is a target for graduating residents, and Level 5 is aspirational and a target for an independent, practicing, EM physician. ${ }^{9}$

Currently, residency program leadership, in conjunction with the ACGME-mandated Clinical Competency Committee, determines individual resident competence with regard to milestones. However, with incoming residents, there is a significant lag of 6-12 months before they can be adequately assessed on all Level 1 milestones. To address the potential gaps and variations in the medical school training of incoming residents, most residencies employ variations of an intern orientation. While the end point of this approach is to standardize the level of the incoming residents, it is challenging to accurately gauge their beginning level of familiarity and competence and tangible deficits do exist. ${ }^{10}$

To develop discipline-specific competencies for graduating medical students, there has been a recent trend to establish specialty-specific boot camps - currently advocated primarily by surgical specialties. ${ }^{11-14}$ The goal of these boot camps is to provide individualized learning, prepare students for entering residency, and address the variability of skills of students attending the program from different medical schools. A recent meta-analysis evaluating the literature on 15 such boot camps showed that participants had significant improvements in clinical skills, knowledge, and confidence. ${ }^{14}$

An EM boot camp may be necessary to prepare medical students who match into EM. ${ }^{10}$ It is, however, not clear as to what gaps currently exist in the undergraduate medical curricula, and therefore, what issues need to be addressed in this boot camp. Our project's goal was therefore to perform a needs assessment to inform the design of an EM boot camp curriculum. Toward this goal, we 1) mapped the core EPAs for graduating medical students to the EM residency Level 1 milestones in order to identify the possible gaps/needs and 2) conducted a pilot procedure workshop that was designed to address some of the identified gaps/needs in procedural skills.

Since institutional variability exists, we used the hypothesis that the core EPAs outline competencies for every graduating medical student (regardless of medical school) and provide mapping to the EM milestone Level 1 competencies for an entering resident, which will help us identify some 
of the overall gaps. Based on a literature review, we also identified core procedural skills and areas of critical importance for the clinical practice of EM and finally, described our pilot EM procedure boot camp..$^{6,9,15,16}$

\section{Methods}

Institutional review board approval and participant consent was not necessary for this study, as the work was part of an elective curriculum. Description of the needs assessment for EM boot camp curriculum, mapping, and procedure workshop is detailed in the following section:

\section{Needs assessment for EM boot camp curriculum}

A systematic approach was used in order to identify the gaps in medical education and to identify topics that would be essential for inclusion in an EM boot camp curriculum. This approach was centered on: 1) identifying gaps between the EPAs and EM milestones (Level 1) and 2) determining what essential and supplemental competencies and skills an incoming EM resident should ideally possess. Based on this information, a pilot 1-day EM procedure boot camp was implemented to address procedural skills and to assess interest and effectiveness. A 2-week structured EM boot camp curriculum is now being conceptualized based on this needs assessment and is planned for implementation in the academic year 2016 .

\section{Mapping of EPAs to EM Level I milestones}

The authors, with expertise in both undergraduate and graduate medical education, collectively reviewed the EPAs and EM milestones. The individual milestones were sequentially mapped to EPAs based on a review of milestones under each sub-competency (Table 1). Each EPA is addressed by at least one EM milestone, while some milestones map to multiple EPAs. However, some milestones are not addressed by any of the EPAs. Table S1 describes mapping in further detail.

\section{Identification of core procedural skills}

We reviewed existing procedural EM milestones and identified an additional list of core procedures that all incoming first-year EM residents should have exposure to and some ability to perform with supervision - not competence. This list was further advised by existing literature (Table 2). ${ }^{15}$

Table I Core Entrustable Professional Activity (EPA) for Entering Residency vs ACGME milestones for emergency medicine residents 6,9

\begin{tabular}{|c|c|c|c|c|c|c|c|c|c|c|c|c|c|}
\hline & EPA I & EPA 2 & EPA 3 & EPA 4 & EPA 5 & EPA 6 & EPA 7 & EPA 8 & EPA 9 & EPA 10 & EPA I I & EPA I 2 & EPA I3 \\
\hline $\mathrm{PCl}$ & & & & & & & & & & $x$ & & & \\
\hline PC2 & $x$ & & & & & $x$ & & & & & & & \\
\hline PC3 & & & $x$ & & & & & & & & & & \\
\hline PC4 & & $x$ & & & & & & & & & & & \\
\hline PC5 & & & & $x$ & & & & & & & & & \\
\hline \multicolumn{14}{|l|}{ PC6* } \\
\hline \multicolumn{14}{|l|}{ PC7* } \\
\hline PC8 & & & & & & & & & & $x$ & & & \\
\hline PC9 & & & & & & & & & & & $x$ & $x$ & \\
\hline \multicolumn{14}{|l|}{$\mathrm{PCI} 0^{*}$} \\
\hline \multicolumn{14}{|l|}{ PCII* } \\
\hline \multicolumn{14}{|l|}{$\mathrm{PCI} 2 *$} \\
\hline \multicolumn{14}{|l|}{ PCI3* } \\
\hline $\mathrm{PCI} 4$ & & & & & & & & & & & & $x$ & \\
\hline MK & & & & & & & & & & $x$ & & & \\
\hline SBPI & & & & & & & & & & & & & $x$ \\
\hline SBP2 & & & & & & & & & & & & & $x$ \\
\hline SBP3 & & & & & $x$ & & & & & & & & \\
\hline PBLI & & & & & & & $x$ & & & & & & \\
\hline PROFI & $x$ & & & & & & & & & & & & \\
\hline \multicolumn{14}{|l|}{ PROF2* } \\
\hline ICSI & $x$ & & & & & & & & & & & & \\
\hline ICS2 & & & & & & $x$ & & $x$ & $x$ & & & & \\
\hline
\end{tabular}

Notes: An "X" at the intersection indicates that the milestone is specifically covered by that EPA. *Indicates milestones that did not map to an EPA.

Abbreviations: EPA, Entrustable Professional Activity; PC, patient care; MK, medical knowledge; SBP, systems-based practice; PBLI, practice-based performance improvement; PROF, professionalism; ICS, interpersonal and communication skills; ACGME, Accreditation Council for Graduate Medical Education. 


\section{Identification of key clinical conditions requiring reinforcement}

Clinical conditions in EPA 10 were reviewed and supplemented with ten emergent conditions recommended by the Clerkship Directors in Emergency Medicine (CDEM) Curriculum Revision Group. ${ }^{16}$ Author consensus determined the core list to be included in the EM boot camp curriculum (Table 3).

\section{Pilot I-day EM procedure boot camp}

In this pilot boot camp, we focused on one aspect of the EM boot camp curriculum for graduating medical students: core procedures fundamental to EM practice. The procedure boot camp was a voluntary, noncredit full-day event. The curriculum had goals and objectives centered on the concept of advanced ABCs. A pretest and survey assessing knowledge and preparedness, confidence, and perceived competence were conducted prior to the workshop. We used a flipped classroom approach where students were expected to review procedures using posted text and videos prior to the session. In a traditional lecture method, the material is presented in the classroom and students later apply this knowledge on their own. Flipping the classroom is different since students gain exposure to material or content outside of class, usually via prereading or online videos, and use class time with a facilitator to apply that knowledge, through problem-solving and practice of skills. The hands-on practice was conducted at three stations in our Simulation Center using task trainers and animal models such as porcine tracheas and ribs (Table 4).

A posttest and a psychomotor skills test were performed using three simulation cases to assess the competence of students in practicing ABC skills (Table S2 - sample checklist

Table 2 Procedures 9,15

\begin{tabular}{ll}
\hline $\begin{array}{l}\text { Milestone-guided procedural } \\
\text { skills (Level I) }\end{array}$ & $\begin{array}{l}\text { Supplemental procedures } \\
\text { warranting exposure }\end{array}$ \\
\hline Arterial puncture & Basic life support \\
Bag-valve mask ventilation & Cricothyrotomy \\
Basic airway management & Direct and video laryngoscopy \\
Emergency ultrasound - & Electrocardiogram \\
indications only & interpretation \\
Local anesthesia & Intraosseous catheter insertion \\
Peripheral intravenous line & Paracentesis \\
Simple interrupted suture & Plain radiography (X-ray) \\
& interpretation \\
Venipuncture & Rescue airways \\
& Thoracentesis \\
& Thoracostomy tube placement \\
& Ultrasound-guided central line \\
& placement \\
& Ultrasound-guided peripheral \\
& intravenous line \\
\hline
\end{tabular}

Table 3 Clinical conditions $s^{6,16}$

\begin{tabular}{ll}
\hline EPA I 0 guided & Supplemental conditions \\
\hline Chest pain & Abdominal pain \\
Electrolyte abnormalities & Cardiac arrest \\
Fever & Gastrointestinal bleeding \\
Hypoglycemia and hyperglycemia & Headache \\
Hypotension and hypertension & Poisoning \\
Mental status changes & Respiratory distress \\
Oliguria, anuria, and urinary retention & Shock \\
Shortness of breath and hypoxemia & Trauma \\
Tachycardia and arrhythmias & \\
\hline
\end{tabular}

Abbreviation: EPA, Entrustable Professional Activity.

for intubation). A post-workshop survey assessed student perception and satisfaction (Table S3).

\section{Results}

Nine of the 15 EM-matched seniors at our institution attended the voluntary, noncredit procedure workshop. The majority of students reported their motivation as "I don't want to suck come July" when residency starts. They held expectations of becoming more comfortable with the procedures, and did not expect competence to develop in 1 day. A post-workshop survey assessed student perception and satisfaction on six domains: meeting objectives, training environment, simulation equipment/supplies, instructor preparedness/facilitation, knowledge acquisition/application, and overall experience. All (100\%) participants reported satisfaction with the overall simulation experience, felt the workshop met goals, and increased their knowledge and confidence in topics covered. Additionally, $100 \%$ of the participants felt the content covered was appropriate for their level of training. Students reported an increased confidence post-workshop in the following procedures: intubation (1.5-2.1), thoracostomy (1.1-1.9), and ultrasound-guided central venous catheterization of internal jugular vein (1.3-2) (a three-point Likert-type scale, with $1=$ not yet confident/able to perform with supervision to $3=$ confident/able to perform without supervision). Psychomotor skills testing of procedures showed that on average, 2.3 (26\%) of students required verbal prompting with performance errors, 4.3 (48\%) worked independently with minor performance errors, and 2.3 (26\%) worked independently without performance errors. Openended comments included: "excellent", "very valuable", "just in time", "great practice", "timely", "we need more training like this", and "best day in medical school yet". Some did report they could allocate more time for practice.

\section{Discussion}

EM-related competencies in medical school curricula may lack uniformity and standardization. ${ }^{16}$ As such, it may not be surprising to see that significant variability exists in the basic 
Table 4 Objectives and stations for procedure workshop

\begin{tabular}{|c|c|}
\hline Procedure workshop station & $\begin{array}{l}\text { Objectives } \\
\text { At the end of session, learner will be able to: }\end{array}$ \\
\hline $\begin{array}{l}\text { Airway management } \\
\text { Emergency medicine milestones } \\
\text { - Patient care (PCI0) - airway management } \\
\text { - Patient care (PC9) - general approach to procedures }\end{array}$ & $\begin{array}{l}\text { I. List the indications for acute airway management } \\
\text { 2. Identify equipment commonly used in airway management including: bag-valve masks, } \\
\text { laryngoscopes, airway adjuncts, rescue equipment } \\
\text { 3. Describe upper airway anatomy } \\
\text { 4. List the steps necessary to prepare a patient for endotracheal intubation } \\
\text { 5. Demonstrate proper technique for endotracheal intubate using direct laryngoscopy, } \\
\text { video laryngoscopy, and boogie-assisted intubation } \\
\text { 6. Confirm proper tube placement using multiple modalities } \\
\text { 7. List the indications, risks, benefits, and alternatives for cricothyrotomy } \\
\text { 8. Demonstrate appropriate preparation and technique to perform needle and surgical } \\
\text { cricothyrotomy }\end{array}$ \\
\hline $\begin{array}{l}\text { Breathing management } \\
\text { Emergency medicine milestones } \\
\text { - Patient care (PC9) - general approach to procedures } \\
\text { - Patient care (PCI0) - airway management }\end{array}$ & $\begin{array}{l}\text { I. List indications, risks, and benefits for tube thoracostomy } \\
\text { 2. Demonstrate the proper preparation and technique for tube thoracostomy } \\
\text { 3. Identify indications for thoracentesis } \\
\text { 4. Demonstrate the proper preparation and technique for thoracentesis } \\
\text { 5. Demonstrate proper technique to position a patient for bag-valve mask ventilation } \\
\text { and endotracheal intubation }\end{array}$ \\
\hline $\begin{array}{l}\text { Circulation management } \\
\text { Emergency medicine milestones } \\
\text { - Patient care (PC9) - general approach to procedures } \\
\text { - Patient care (PCI2) - goal-directed focused ultrasound } \\
\text { - Patient care (PCI4) - vascular access }\end{array}$ & $\begin{array}{l}\text { I. Identify a patient in need of vascular access } \\
\text { 2. Demonstrate successful placement of peripheral IV line with ultrasound } \\
\text { 3. Identify a patient in need of central venous access } \\
\text { 4. List the risks, benefits, and contraindications of central venous access at each of the } \\
\text { sites: right internal jugular, right subclavian, and femoral veins } \\
\text { 5. Demonstrate the proper preparation and technique for successful central venous } \\
\text { access with and without ultrasound guidance (each of three sites) } \\
\text { 6. List the indication, contraindications, risks, benefits, and alternatives to intraosseous } \\
\text { catheter insertion } \\
\text { 7. Demonstrate proper preparation and insertion of an intraosseous line }\end{array}$ \\
\hline
\end{tabular}

Abbreviation: IV, intravenous.

knowledge and skills of incoming EM residents. The resulting gap in expected versus actual skill sets is of concern to educators, supervising clinicians, and the public. A standardized EM boot camp may help mitigate these deficiencies by developing specialty-specific competencies. Currently, there is no existing framework for the setting up of an EM boot camp. We looked to the EPAs, EM resident milestones, and competencies for guidance to inform the design of a proposed EM boot camp curriculum. ${ }^{6,9}$

Mapping the core EPAs to the EM milestone Level 1 competencies for the entering residents helped to: 1) determine that there likely exists a need for an EM-specific boot camp and 2) identify some of the specific gaps/needs to be addressed by the boot camp curriculum. Seven of the 23 EM-specific milestones did not map to the EPAs (Table 1). Five (PC 6, PC 10, PC 11, PC 12, and PC 13) of these seven are uniquely tied to EM practice. Since EPAs outline general competencies and are not discipline-specific, these gaps are not unexpected. Two competencies, PC 7 and PROF 2, are general and apply across disciplines, but did not map to a corresponding EPA. Admittedly, these are included in categories likely to be covered well in medical school, but there are specific issues unique to EM that fall under these domains.
For example, patient disposition (PC 7) is integral to daily EM practice and therefore would need to be addressed.

Based on our mapping, it is clear that any proposed EM boot camp should, at a minimum, focus on the key gap areas related to EM, such as airway management, pain management, procedural sedation, ultrasound, and patient observation in the emergency department (ED), reassessment, and disposition. Practice and instruction - in the list of core procedures and clinical competencies - that we have identified here would also be beneficial. Finally, there is a need for reinforcement of general, but essential topics such as patientcentered communication and professionalism. For example, timely chart completion, duty hour reporting, and procedure logging (PROF 2) should be addressed in a proposed EM boot camp. A Professionalism in Residency session to address the development of the professional identity of trainees as EM physicians would be similarly beneficial.

We identified some supplemental topics based on a review of literature on surgery and EM-resident-aimed boot camps. ${ }^{10-12}$ Topics include: advanced cardiac life support skills, medicolegal principles of ED patient care, how to place a patient on a cardiac monitor, work code cart monitors/defibrillators, and perform female genitourinary 
examinations. ${ }^{10,11}$ Advanced topics on orthopedics (splinting), ophthalmology (slit-lamp), and otolaryngology are relevant and may be considered, if time permits. Similarly, high-yield topics such as sepsis, stroke, and asthma may be reviewed to help students critically understand the current status and best practices.

It is important to note that boot camps themselves may be subject to variability and inconsistencies that may limit their generalizability across programs. Therefore, we propose a core standardized EM boot camp curriculum across schools to help optimize learning outcomes.

\section{Future perspectives}

The focus areas identified based on the mapping of the core EPAs to the EM milestone, the list of conditions and procedures selected based on literature review, and the feedback obtained from the pilot procedure boot camp is guiding the design of a formal, for-credit, 2-week EM boot camp at our institution that will allow for adequate time to teach, practice, and assess skills. Since many schools cap the number of weeks a student can rotate with a specific department, we recommend that the boot camp be approved under the Office of Education or equivalent so that students are not forced to make difficult choices.

We plan a variety of educational modalities to deliver this proposed boot camp: lectures, podcasts, and videos for flipped classroom e-learning; small group discussions; procedure workshops; and simulations (manikin and standardized patients). Expected resources will include faculty/residents to facilitate, equipment, space, and a budget for supplies. Pre- and post-assessments of knowledge and skills, as well as direct observation, will assess the effectiveness of this curriculum.

\section{Conclusion}

Mapping the Core EPAs for Entering Residency to the EM milestones at Level 1 identifies educational gaps for graduating medical students. Gaps include procedural skills such as airway management, procedural sedation, pain management, care of wounds, suturing, and emergency ultrasound, as well as ED-specific skills related to patient reassessment, observation, and disposition. Educators seeking to design EM boot camps for medical students should consider the identified gaps, procedures, and clinical conditions during the development of a core standardized curriculum.

\section{Disclosure}

The authors report no conflicts of interest in this work.

\section{References}

1. The National Resident Matching Program. Advanced Data Table for the 2015 Main Residency Match. March 20, 2015. Available from: http://www.nrmp.org/wp-content/uploads/2015/03/ADT2015_final. pdf. Accessed April 30, 2015.

2. Wald DA, Lin M, Manthey DE, Rogers RL, Zun LS, Christopher T. Emergency medicine in the medical school curriculum. Acad Emerg Med. 2010;17:S26-S30.

3. Manthey DE, Coates WC, Ander DS, et al. Report of the task force on national fourth year medical student emergency medicine curriculum guide. Ann Emerg Med. 2006;47(3):e1-e7.

4. Lyss-Lerman PM, Teherani AP, Aagaard EM, Loeser HM, Cooke MM, Harper GMM. What training is needed in the fourth year of medical school? Views of residency program directors. Acad Med. 2009;84(7):823-829.

5. Englander R, Cameron T, Ballard AJ, Dodge J, Bull J, Aschenbrener CA. Toward a common taxonomy of competency domains for the health professions and competencies for physicians. Acad Med. 2013;88(8):1088-1094.

6. AAMC Drafting Panel for Core Entrustable Professional Activities for Entering Residency. Core Entrustable Professional Activities for Entering Residency Curriculum Developers' Guide. 2014. Available from: https:// members.aamc.org/eweb/DynamicPage.aspx?Action=Add\&Object KeyFrom=1A83491A-9853-4C87-86A4-F7D95601C2E2\&WebCode= PubDetailAdd $\&$ DoNotSave $=$ yes $\&$ ParentObject $=$ CentralizedOrderEn try\&ParentDataObject=Invoice\%20Detail\&ivd_formkey=6920279263d7-4ba2-bf4e-a0da41270555\&ivd_prc_prd_key=E3229B10-BFE74B35-89E7-512BBB01AE3B. Accessed February 5, 2015.

7. ten Cate O. Entrustability of professional activities and competencybased training. Med Educ. 2005;39(12):1176-1177.

8. ten Cate O. Nuts and bolts of entrustable professional activities. $J$ Grad Med Educ. 2013;5(1):157-158.

9. ACGME and ABEM. The Emergency Medicine Milestone Project. December 2012. Available from: https://www.abem.org/public/ docs/default-source/migrated-documents-and-files/em-milestones. pdf?sfvrsn=4. Accessed November 2015.

10. Santen SA, Rademacher N, Heron SL, Khandelwal S, Hauff S, Hopson L. How competent are emergency medicine interns for Level 1 milestones: who is responsible? Acad Emerg Med. 2013;20(7):736-739.

11. Ataya R, Dasgupta R, Blanda R, Moftakhar Y, Hughes PG, Ahmed R. Emergency medicine residency boot camp curriculum: a pilot study. West J Emerg Med. 2015;16(2):356-361.

12. ACS/APDS/ASE Resident Prep Curriculum - Goals and Objectives. American College of Surgeons Website. April 2014. Available from: https://www.facs.org/education/program/resident-prep. Accessed March 30, 2015.

13. Selden NR, Origitano TC, Burchiel KJ, et al. A national fundamentals curriculum for neurosurgery PGY1 residents: The 2010 Society of Neurological Surgeons boot camp courses. Neurosurgery. 2012;70(4):971-981.

14. Blackmore C, Austin J, Lopushinsky SR, Donnon T. Effects of postgraduate medical education "boot camps" on clinical skills, knowledge, and confidence: a meta-analysis. J Grad Med Educ. December 2014;6(4):643-652.

15. Santen SA, Peterson WJ, Khandelwal S, House JB, Manthey DE, Sozener CB. Medical student milestones in emergency medicine. Acad Emerg Med. 2014;21(8):905-911.

16. Manthey DE, Ander DS, Gordon DC, et al. Emergency medicine clerkship curriculum: an update and revision. Acad Emerg Med. 2010;17(6):638-643. 


\section{Supplementary materials}

Table SI Detailed mapping and comparison of Core Entrustable Professional Activity for Entering Residency vs ACGME milestones for Emergency Medicine residents 6

\begin{tabular}{|c|c|c|}
\hline Overall competency & Milestone at Level I & Core EPA \\
\hline $\begin{array}{l}\mathrm{PCI} \text { : Emergency stabilization } \\
\text { Prioritizes critical initial stabilization action and mobilizes } \\
\text { hospital support services in the resuscitation of a critically ill } \\
\text { or injured patient and reassesses after stabilizing intervention }\end{array}$ & Recognizes abnormal vital signs & $\begin{array}{l}\text { EPA I0: Recognize a patient } \\
\text { requiring urgent or emergent } \\
\text { care and initiate evaluation } \\
\text { and management }\end{array}$ \\
\hline $\begin{array}{l}\text { PC2: Performance of focused history and physical exam } \\
\text { Abstracts current findings in a patient with multiple chronic } \\
\text { medical problems and, when appropriate, compares with a prior } \\
\text { medical record and identifies significant differences between the } \\
\text { current presentation and past presentations }\end{array}$ & $\begin{array}{l}\text { Performs and communicates a } \\
\text { reliable, comprehensive history and } \\
\text { physical exam }\end{array}$ & $\begin{array}{l}\text { EPA I: Gather a history and } \\
\text { perform a physical examination } \\
\text { EPA 6: Provide an oral } \\
\text { presentation of a clinical } \\
\text { encounter }\end{array}$ \\
\hline $\begin{array}{l}\text { PC3: Diagnostic studies } \\
\text { Applies the results of diagnostic testing based on the probability } \\
\text { of disease and the likelihood of test results altering management }\end{array}$ & $\begin{array}{l}\text { Determines the necessity of } \\
\text { diagnostic studies }\end{array}$ & $\begin{array}{l}\text { EPA 3: Recommend and } \\
\text { interpret common diagnostic } \\
\text { and screening tests }\end{array}$ \\
\hline $\begin{array}{l}\text { PC4: Diagnosis } \\
\text { Based on all available data, narrows and prioritizes the list } \\
\text { of weighted differential diagnoses to determine appropriate }\end{array}$ & $\begin{array}{l}\text { Constructs a list of potential diagnoses } \\
\text { based on chief complaint and initial } \\
\text { assessment }\end{array}$ & $\begin{array}{l}\text { EPA 2: Prioritize a differential } \\
\text { diagnosis following a clinical } \\
\text { encounter }\end{array}$ \\
\hline
\end{tabular}

management

PC5: Pharmacotherapy

Selects and prescribes appropriate pharmaceutical agents based upon relevant considerations such as mechanism of action, intended effect, financial considerations, possible adverse effects, patient preferences, allergies, potential drug-food and drug-drug interactions, institutional policies, and clinical guidelines

PC6: Observation and reassessment

Reevaluates patients undergoing ED observation (and monitoring) and using appropriate data and resources, determines the differential diagnosis, treatment plan, and disposition

PC7: Disposition

Establishes and implements a comprehensive disposition plan that uses appropriate consultation resources; patient education regarding diagnosis; treatment plan; medications; and time- and location-specific disposition instructions PC8: Multitasking (task-switching)

Employs task switching in an efficient and timely manner in order to manage the ED

PC9: General approach to procedures

Performs the indicated procedure on all appropriate patients (including those who are uncooperative, at the extremes of age, hemodynamically unstable and those who have multiple comorbidities, poorly defined anatomy, high risk for pain or procedural complications, sedation requirement), takes steps to avoid potential complications, and recognizes the outcome and/or complications resulting from the procedure

PCI0: Airway management

Performs airway management on all appropriate patients (including those who are uncooperative, at the extremes of age, hemodynamically unstable and those who have multiple comorbidities, poorly defined anatomy, high risk for pain or procedural complications, sedation requirement), takes steps to avoid potential complications, and recognize the outcome and/or complications resulting from the procedure

Knows the different classifications of pharmacologic agents and their mechanism of action. Consistently asks patient for drug allergies

Recognizes the need for patient reevaluation

Describes basic resources available for care of the emergency department patient

Manages a single patient amidst distractions

Identifies pertinent anatomy and physiology for a specific procedure; uses appropriate universal precautions

Describes upper airway anatomy; Performs basic airway maneuvers or adjuncts (jaw thrust/chin lift/oral airway/nasopharyngeal airway) and ventilates/oxygenates patient using BVM
EPA 4: Enter and discuss order and prescriptions
None

EPA 10: Recognize a patient requiring urgent or emergent care and initiate evaluation and management

EPA I I: Obtain informed consent for tests and/or procedures EPA 12: Perform general procedures of a physician 
Table SI (Continued)

Overall competency
PCII: Anesthesia and acute pain management
Provides safe acute pain management, anesthesia, and
procedural sedation to patients of all ages regardless of
the clinical situation

PCI2: Other diagnostic and therapeutic procedures: goal-directed focused ultrasound (diagnostic/procedural) Uses goal-directed focused ultrasound for the bedside diagnostic evaluation of emergency medical conditions and diagnoses, resuscitation of the acutely ill or injured patient, and procedural guidance

PCI3: Other diagnostic and therapeutic procedures: wound management

Assesses and appropriately manages wounds in patients of all ages regardless of the clinical situation

PCI4: Other diagnostic and therapeutic procedures: vascular access

Successfully obtains vascular access in patients of all ages regardless of the clinical situation

MK: Medical knowledge

Demonstrates appropriate medical knowledge in the care of emergency medicine patients

SBPI: Patient safety

Participates in performance improvement to optimize patient safety

SBP2: Systems-based management

Participates in strategies to improve health care delivery and flow. Demonstrates an awareness of and responsiveness to the larger context and system of health care SBP2: Technology

Uses technology to accomplish and document safe health care delivery

PBLI: Practice-based performance improvement Participates in performance improvement to optimize ED function, self-learning, and patient care

PROFI: Practice-based performance improvement Participates in performance improvement to optimize ED function, self-learning, and patient care

PROF2: Accountability

Demonstrates accountability to patients, society, profession, and self
Milestone at Level I

Discusses with the patient indications,

contraindications, and possible

complications of local anesthesia;

performs local anesthesia using appropriate doses of local anesthetic and appropriate technique to provide skin to subdermal anesthesia for procedures

Describes the indications for emergency ultrasound

Prepares a simple wound for suturing (identify appropriate suture material, anesthetize wound and irrigate); demonstrates sterile technique; places a simple interrupted suture Performs a venipuncture; places a peripheral intravenous line; performs an arterial puncture

Passes initial national licensing examinations (eg, USMLE Step I and Step 2 or COMLEX Level I and Level 2)

Adheres to standards for maintenance of a safe working environment; describes medical errors and adverse events

Describes members of ED team

(eg, nurses, technicians, security)

Uses the Electronic Health Record (EHR) to order tests, medications, and document notes, and respond to alerts; reviews medications for patients Describes basic principles of evidence-based medicine

Demonstrates behavior that conveys caring, honesty, genuine interest, and tolerance when interacting with a diverse population of patients and families

Demonstrates basic professional responsibilities such as timely reporting for duty, appropriate dress/grooming, rested and ready to work, delivery of patient care as a functional physician; maintains patient confidentially; uses social media ethically and responsibly; adheres to professional responsibilities, such as conference attendance, timely chart completion, duty hour reporting, procedure reporting
Core EPA

None

None

None

EPA 12: Perform general procedures of a physician

Not applicable

EPA 13: Identify system failures and contribute to a culture of safety and improvement

EPA 13: Identify system failures and contribute to a culture of safety and improvement

EPA 5: Document a clinical encounter in the patient record

EPA 7: Form clinical questions and retrieve evidence to advance patient care EPA I: Gather a history and perform a physical examination

None 
Table SI (Continued)

\begin{tabular}{|c|c|c|}
\hline Overall competency & Milestone at Level I & Core EPA \\
\hline $\begin{array}{l}\text { ICSI: Patient-centered communication } \\
\text { Demonstrates interpersonal and communication skills that } \\
\text { result in the effective exchange of information and } \\
\text { collaboration with patients and their families } \\
\text { ICS2: Team management } \\
\text { Leads patient-centered care teams, ensuring effective } \\
\text { communication and mutual respect among members } \\
\text { of the team }\end{array}$ & $\begin{array}{l}\text { Establishes rapport with and } \\
\text { demonstrate empathy toward patients } \\
\text { and their families; listens effectively to } \\
\text { patients and their families } \\
\text { Participates as a member of a patient } \\
\text { care team }\end{array}$ & $\begin{array}{l}\text { EPA 6: Provide an oral } \\
\text { presentation of a clinical } \\
\text { encounter } \\
\text { EPA 8: Give or receive a } \\
\text { patient handover to transition } \\
\text { care responsibility } \\
\text { EPA 9: Collaborate } \\
\text { as a member of an } \\
\text { interprofessional team }\end{array}$ \\
\hline
\end{tabular}

Abbreviations: EPA, Entrustable Professional Activity; PC, patient care; MK, medical knowledge; SBP, systems-based practice; PBLI, practice-based performance improvement; PROF, professionalism; ICS, interpersonal and communication skills; ED, emergency department; BVM, bag-valve mask; ACGME, Accreditation Council for Graduate Medical Education; USMLE, United States Medical Licensing Examination; COMLEX, Comprehensive Osteopathic Medical Licensing Examination.

Table S2 Intubation competency evaluation

\begin{tabular}{|c|c|c|c|}
\hline Critical actions & $\begin{array}{l}\text { Requires verbal } \\
\text { prompting with } \\
\text { performance errors } \\
0\end{array}$ & $\begin{array}{l}\text { Works independently } \\
\text { with minor } \\
\text { performance errors } \\
\text { I }\end{array}$ & $\begin{array}{l}\text { Works independently } \\
\text { without performance } \\
\text { errors } \\
2\end{array}$ \\
\hline $\begin{array}{l}\text { Consider the indication for intubation (Is positive } \\
\text { airway pressure CPAP/BIPAP an option?) (do-not-intubate } \\
\text { status; consent) }\end{array}$ & $\square$ & $\square$ & $\square$ \\
\hline $\begin{array}{l}\text { Pre-oxygenate with high-flow oxygen ( } 3 \text { minutes or } \\
\text { eight deep breaths) }\end{array}$ & $\square$ & $\square$ & $\square$ \\
\hline $\begin{array}{l}\text { Assess for difficult laryngoscopy, difficult bag-valve } \\
\text { mask, difficult supraglottic airway device }\end{array}$ & $\square$ & $\square$ & $\square$ \\
\hline $\begin{array}{l}\text { If suspected difficult airway and time allows, consider } \\
\text { awake technique and/or call for help }\end{array}$ & $\square$ & $\square$ & $\square$ \\
\hline Check for dentures & $\square$ & $\square$ & $\square$ \\
\hline Position patient (ramped/sniff) & $\square$ & $\square$ & $\square$ \\
\hline Continuous monitoring & $\square$ & $\square$ & $\square$ \\
\hline Start IV access ( $\times 2$ preferably) & $\square$ & $\square$ & $\square$ \\
\hline Administer $\mathrm{O}_{2}$ via nasal cannula for apneic oxygenation & $\square$ & $\square$ & $\square$ \\
\hline Set up equipment: & $\square$ & $\square$ & $\square$ \\
\hline \multicolumn{4}{|l|}{$\begin{array}{l}\text { Bag-valve mask, naso/oropharygeal airway, suction, } \\
\text { laryngoscope, blade, capnometer, endotracheal tube, } \\
\text { stylet, adjuncts, difficult airway equipment }\end{array}$} \\
\hline Drugs (rapid sequence induction) & $\square$ & $\square$ & $\square$ \\
\hline Personnel & $\square$ & $\square$ & $\square$ \\
\hline Ventilator and settings & $\square$ & $\square$ & $\square$ \\
\hline Tube placement verification & $\square$ & $\square$ & $\square$ \\
\hline Secure endotracheal tube & $\square$ & $\square$ & $\square$ \\
\hline $\begin{array}{l}\text { Verbalize response: "What are next steps to ensure } \\
\text { a safe intubation?" }\end{array}$ & Sedation & CXR & $\begin{array}{l}\text { Blood gas q30 minutes } \\
\text { post-intubation }\end{array}$ \\
\hline & $\square$ & $\square$ & $\square$ \\
\hline
\end{tabular}

Abbreviations: CPAP, continuous positive airway pressure; BIPAP, biphasic positive airway pressure; IV, intraveneous; CXR, chest X-ray. 
Table S3 The advanced ABCs: a residency preparatory workshop-post-workshop survey

Please complete this anonymous evaluation by assigning each statement a number corresponding to your opinion and placing a checkmark in the appropriate box. Your opinion matters and will assist us in developing quality instruction to improve educational and patient care outcomes. Thank you for taking the time to complete this form

\begin{tabular}{|c|c|c|c|c|c|}
\hline & Strongly disagree & Disagree & Neutral & Agree & Strongly agree \\
\hline \multicolumn{6}{|l|}{ Training environment } \\
\hline Was safe and nonthreatening & $\square$ & $\square$ & $\square$ & $\square$ & $\square$ \\
\hline \multicolumn{6}{|l|}{ Procedure workshop station(s) } \\
\hline Objectives were clearly defined & $\square$ & $\square$ & $\square$ & $\square$ & $\square$ \\
\hline Were well organized & $\square$ & $\square$ & $\square$ & $\square$ & $\square$ \\
\hline Were appropriately paced & $\square$ & $\square$ & $\square$ & $\square$ & $\square$ \\
\hline Met my goal and expectations & $\square$ & $\square$ & $\square$ & $\square$ & $\square$ \\
\hline The podcasts helped me prepare for the SIM session & $\square$ & $\square$ & $\square$ & $\square$ & $\square$ \\
\hline Were appropriate for my level of training & $\square$ & $\square$ & $\square$ & $\square$ & $\square$ \\
\hline Were appropriately paced & $\square$ & $\square$ & $\square$ & $\square$ & $\square$ \\
\hline \multicolumn{6}{|l|}{ Simulation and clinical equipment/supplies } \\
\hline Were adequate & $\square$ & $\square$ & $\square$ & $\square$ & $\square$ \\
\hline Were realistic & $\square$ & $\square$ & $\square$ & $\square$ & $\square$ \\
\hline Added value to the learning experience & $\square$ & $\square$ & $\square$ & $\square$ & $\square$ \\
\hline \multicolumn{6}{|l|}{ Instructor(s) } \\
\hline Were knowledgeable about the subject & $\square$ & $\square$ & $\square$ & $\square$ & $\square$ \\
\hline Were prepared to facilitate this activity & $\square$ & $\square$ & $\square$ & $\square$ & $\square$ \\
\hline Facilitated in a way that helped me learn & $\square$ & $\square$ & $\square$ & $\square$ & $\square$ \\
\hline Encouraged participation and collaboration & $\square$ & $\square$ & $\square$ & $\square$ & $\square$ \\
\hline Were enthusiastic about this activity & $\square$ & $\square$ & $\square$ & $\square$ & $\square$ \\
\hline Encouraged learner's questions & $\square$ & $\square$ & $\square$ & $\square$ & $\square$ \\
\hline \multicolumn{6}{|c|}{ Learner(s) - "After the procedure workshop[...]" } \\
\hline \multicolumn{6}{|c|}{ I am more familiar with the indications/contraindications/complications/technique and equipment associated with: } \\
\hline Bag-valve mask ventilation & $\square$ & $\square$ & $\square$ & $\square$ & $\square$ \\
\hline Naso/oropharyngeal airway & $\square$ & $\square$ & $\square$ & $\square$ & $\square$ \\
\hline Direct laryngoscopy & $\square$ & $\square$ & $\square$ & $\square$ & $\square$ \\
\hline Laryngeal mask airway & $\square$ & $\square$ & $\square$ & $\square$ & $\square$ \\
\hline Bougie & $\square$ & $\square$ & $\square$ & $\square$ & $\square$ \\
\hline Video laryngoscopy & $\square$ & $\square$ & $\square$ & $\square$ & $\square$ \\
\hline Cricothyrotomy & $\square$ & $\square$ & $\square$ & $\square$ & $\square$ \\
\hline Thoracostomy & $\square$ & $\square$ & $\square$ & $\square$ & $\square$ \\
\hline Thoracentesis & $\square$ & $\square$ & $\square$ & $\square$ & $\square$ \\
\hline Ultrasound-guided central line cannulation & $\square$ & $\square$ & $\square$ & $\square$ & $\square$ \\
\hline Ultrasound-guided peripheral line insertion & $\square$ & $\square$ & $\square$ & $\square$ & $\square$ \\
\hline I have more knowledge & $\square$ & $\square$ & $\square$ & $\square$ & $\square$ \\
\hline I feel more confident & $\square$ & $\square$ & $\square$ & $\square$ & $\square$ \\
\hline \multicolumn{6}{|l|}{ Overall SIM-based workshop experience } \\
\hline The workshop met my goals and expectations & $\square$ & $\square$ & $\square$ & $\square$ & $\square$ \\
\hline I enjoyed the procedure workshop & $\square$ & $\square$ & $\square$ & $\square$ & $\square$ \\
\hline I want more opportunities to learn using simulation & $\square$ & $\square$ & $\square$ & $\square$ & $\square$ \\
\hline I would recommend this teaching tool to others & $\square$ & $\square$ & $\square$ & $\square$ & $\square$ \\
\hline
\end{tabular}

Comments:

Advances in Medical Education and Practice

Dovepress

\section{Publish your work in this journal}

Advances in Medical Education and Practice is an international, peerreviewed, open access journal that aims to present and publish research on Medical Education covering medical, dental, nursing and allied health care professional education. The journal covers undergraduate education, postgraduate training and continuing medical education including emerging trends and innovative models linking education, research, and health care services. The manuscript management system is completely online and includes a very quick and fair peer-review system. Visit http://www.dovepress.com/testimonials.php to read real quotes from published authors.

Submit your manuscript here: http://www.dovepress.com/advances-in-medical-education-and-practice-journal 